Jurnal Sistem Informasi (Journal of Information Systems). 2/12 (2016), 95-103

DOI: http://dx.doi.org/10.21609/jsi.v12i2.484

\title{
TINGKAT KESIAPAN IMPLEMENTASI KNOWLEDGE MANAGEMENT PADA DIVISI TEKNOLOGI INFORMASI PT. "X"
}

\author{
Dwi Atmodjo Wismono Prapto dan Sumiati Hutagalung \\ Program Studi Teknik Informatika, Fakultas Teknologi Informasi, IKPIA Perbanas Jakarta, Jl. Perbanas, \\ RT06/RW07, Jakarta, 12940, Indonesia
}

E-mail: dwi.atmodjo@perbanas.id, hutagalungsumiati@gmail.com

\begin{abstract}
IT Consultants are in the need of knowledge resources from experts who have either tacit, implicit, or explicit. Hence, a system that is able to manage knowledge (Knowledge Management/KM) is required. Along with success stories and failure experienced by many organizations in the implementation of KM system, it indicates that there should be factors that have roles in determining the successes of KM implementation. These factors are highly related to the readiness of the institution or company. Therefore, before implementing $\mathrm{KM}$, it is necessary to analyze the readiness of the institution or organization. Analysis of readiness is expected to give an overview to the management about the state of readiness and aspects related to the successful implementation of KM. This study aims to measure the readiness of KM implementation in IT division in one of the IT consultation firm. The measurement of readiness was based on the extraction results of previous studies from which seven research aspects are obtained to be analyzed. Those aspects are strategy, organization, culture, technology, motivation, process, and human resources. Data was collected by questionnaires while data analysis was performed using descriptive statistical analysis. The analysis showed that the overall implementation of KM in IT division reached a readiness level of 2.26 in implementing KM.
\end{abstract}

Keywords: knowledge management, KM readiness, KM readiness measurement, KM readiness factors

\begin{abstract}
Abstrak
Perusahaan Konsultan bidang IT sangat memerlukan sumberdaya pengetahuan dari tenaga ahli yang dimilikinya baik Tacit, Implicit, maupun Explicit . Untuk keperluan tersebut diperlukan sebuah sistem yang bisa mengelola pengetahuan yang dimiliki oleh tenaga ahli yang ada dalam perusahaan. Namun seiring dengan kisah sukses dan gagal yang dialami banyak organisasi dalam implementasi Knowledge Management Sistem mengidikasikan adanya faktor-faktor yang memiliki peran dalam menentukan keberhasilan implementasi KM. Faktor ini sangat berhubungan dengan kesiapan lembaga atau perusahaan. Oleh karena itu sebelum mengimplementasikan KM perlu dilakukan analisis kesiapan terhadap lembaga atau organisasi yang bersangkutan. Analisis kesiapan tersebut diharapkan dapat memberikan gambaran kepada pihak manajemen mengenai kondisi kesiapan dan aspek-aspek yang terkait dengan keberhasilan implementasi KM. Penelitian ini bertujuan mengukur kesiapan Implementasi KM di DIVISI IT pada konsultan IT dalam mengimplementasikan KM. Pengukuran kesiapan berdasarkan hasil ekstraksi penelitian terdahulu sehingga diperolah tujuh aspek penelitian, yaitu Strategy, Organization, Culture, Technology, Motivation, Process, dan Human Resources. Pengumpulan data dilakukan dengan penyebaran kuesioner, sedangkan analisis data dilakukan dengan teknik analisis statistik deskriptif. Hasil analisis menunjukkan bahwa secara keseluruhan DIVISI IT mencapai tingkat ready (2.26) dalam implementasi KM.
\end{abstract}

Kata Kunci: knowledge management, kesiapan implementasi KM, pengukuran kesiapan KM, faktorfaktor kesiapan KM

\section{Pendahuluan}

Pada dasarnya setiap individu memiliki peran yang unik, baik itu dalam masyarakat, perusahaan, maupun dalam sebuah organisasi. Dalam menjalankan perannya tersebut, masing-masing sumber daya manusia memiliki keahlian dan cara masing-masing. Proses penyelesaian tugas dan tanggung jawab yang dilakukan setiap hari/berulang-ulang se- cara tidak langsung menghasilkan keahlian atau pengetahuan tertentu terhadap bidang tugas dan tanggung jawabnya yang mungkin hanya dimiliki oleh sumber daya tersebut. Keahlian atau pengetahuan jenis ini disebut sebagai tacit knowledge. Tacit knowledge merupakan knowledge personal yang tersimpan didalam kepala setiap orang. Knowledge tersebut terakumulasi melalui proses belajar dan pengalaman. Tacit knowledge berkembang melalui 


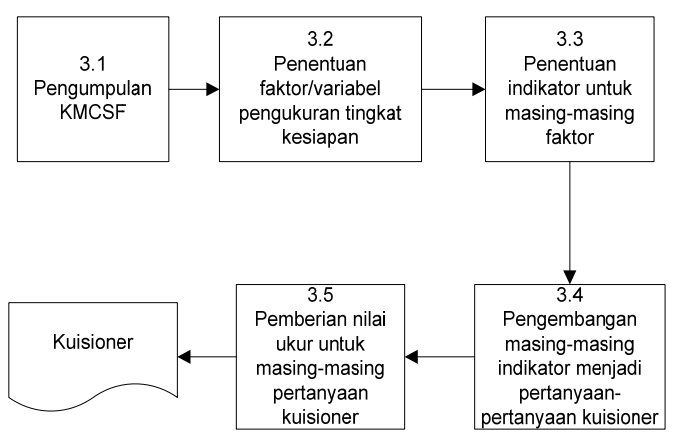

Gambar 1. Metode Penelitian

praktik percobaan, pengalaman akan kegagalan dan keberhasilan akan sesuatu hal.

Dengan tacit knowledge yang dimiliki oleh setiap sumber daya manusia, maka masing-masing sumber daya manusia dapat menghasilkan suatu knowledge yang dapat digunakan untuk menyelesaikan suatu permasalahan dalam perusahaan tersebut, sehingga stabilitas dan performance perusahaan dapat tetap dijaga. Dalam hal ini bisa dilihat bahwa knowledge termasuk sebuah aset yang perlu dirawat oleh organisasi. Knowledge yang dikelola dengan baik akan mempermudah perusahaan dalam mengambil langkah maju karena perusahaan tersebut sudah memiliki kumpulan knowledge yang diperoleh sebelumnya atau mendapat knowledge dari pihak luar.

Pada akhirnya sebuah organisasi membutuhkan sebuah knowledge management (KM) untuk membantu organisasi tersebut menemukan apa yang mereka ketahui, menyadari apa yang mereka ketahui, dan secara efektif dapat menggunakan apa yang mereka ketahui. KM diartikan sebagai sebuah proses yang dapat membantu perusahaan dalam menemukan, memilih, menyebarkan, serta memindahkan informasi penting dan mahal yang biasanya digunakan dalam aktivitas menyelesaikan masalah, untuk pembelajaran, perencanaan strategi, dan pengambilan keputusan. KM dapat berarti pula sebagai sebuah proses untuk menciptakan, memvalidasi, mempresentasikan, mendistribusikan, serta mengaplikasikan. Kreasi dari pengetahuan baru, sharing pengetahuan dan penyebarannya, serta alat dan metode untuk mempromosikannya dapat pula dianggap sebagai pengertian KM menurut Maki [1]. Sementara itu menurut World IQ, KM adalah penggabungan proses antara kreasi, penyebaran, pengujian, integrasi, dan pemanfaatan pengetahuan di dalam suatu perusahaan. Dari beberapa pengertian di atas maka dapat disimpulkan bahwa KM adalah suatu upaya dalam mendokumentasikan dan mengelola segala jenis pengetahuan, pengalaman, maupun ilmu yang berguna bagi suatu perusahaan dalam menyelesaikan suatu masalah untuk kemajuan perusahaan itu sendiri, atau upaya mengeluar- kan tacit knowledge yang ada di pikiran manusia menjadi explicit knowledge yang dikelola dengan baik. Explicit knowledge merupakan knowledge yang tersimpan pada tempat penyimpanan lain selain pikiran manusia.

Namun dengan munculnya kisah sukses dan gagal yang dialami banyak organisasi dalam mengimplementasikan KM, maka organisasi yang hendak mengimplementasikan KM sebaiknya melakukan pengukuran untuk mendapatkan kondisi kesiapan organisasi. Penelitian yang telah dilakukan oleh lembaga telekomunikasi di Inggris (British Telecommunication PLC), sebesar 70\% proyek KM dinyatakan gagal. Hal ini dikarenakan belum siapnya organisasi ketika mengimplementasikan KM. Kegagalan yang sering terjadi disebabkan karena implementasi sistem hanya berdasarkan teori-teori saja dan tidak mempertimbangkan keadaan organisasi [2]. Oleh karena itu sebelum mengimplementasikan KM perlu dilakukan analisis kesiapan. Analisis kesiapan tersebut dapat memberikan gambaran kepada pihak organisasi atau perusahaan mengenai kondisi kesiapan setiap aspek yang terkait dengan implementasi KM. Dari hasil analisis kesiapan inilah pihak pengelola organisasi maupun perusahaan dapat mengambil langkah untuk mempersiapkan aspek-aspek yang dinilai masih kurang siap dalam implementasi KM.

Beberapa penelitian sebelumnya yang berkaitan dengan tingkat kesiapan KM diantaranya adalah penelitian Airlangga Agung Perdana yang berjudul Analisis Pengukuran Tingkat Kesiapan Implementasi Knowledge Management di Pusat Sistem Informasi dan Teknologi Keuangan Kementerian Keuangan [2]. Dalam penelitiannya, Airlangga menyebarkan kuesioner yang dirancang berdasarkan penelitian yang ada sebelumnya oleh Sukomo dan Pandu Arizona [3]. Sementara tingkat kesiapan $\mathrm{KM}$ atau KM readiness level menggunakan tingkat kesiapan KM yang dilakukan oleh Rao [4] dan yang sudah dimodifikasi oleh Zaidiah [5]. Kemudian dilakukan analisis dengan metode statistik deskriptif untuk menentukan tingkat kesiapan KM dan memberikan rekomendasi untuk Pusintek.

Penelitian Pradana Atmadiputra yang berjudul Analisis Tingkat Kesiapan Implementasi Knowledge Management (Knowledge Management Readiness) di Departemen Microsoft Operation PT Astra Graphia Information Technology [6] memetakan KMCSF dari tujuh penelitian sebelumnya. Berdasarkan pemetaan tersebut Pradana menghasilkan tujuh faktor atau variabel kesuksesan KM. Faktor tersebut kemudian dikembangkan menjadi pernyataan-pernyataan yang digunakan dalam kuesioner. Instrumen penilaian yang dilakukan menggunakan skala The Impact of Event Scale-Revised (IES-R). Sementara, tingkat kesiapan KM atau KM readiness level mengadopsi tingkat kesiapan KM 
TABEL 1

\begin{tabular}{|c|c|c|c|c|c|c|}
\hline No & $\begin{array}{l}\text { Ha- } \\
\text { sanali[13] }\end{array}$ & $\begin{array}{l}\text { Mamaghani, Samiza- } \\
\text { deh, Saghafi[14] }\end{array}$ & $\begin{array}{l}\text { Ma- } \\
\text { thi[15] }\end{array}$ & Wong[16] & $\begin{array}{l}\text { Luis Carlos } \\
\text { Cámpiz Mer- } \\
\text { cado[17] }\end{array}$ & Faktor Kunci Sukes \\
\hline 1 & H1 & - & - & W1 & L2 & Leadership \\
\hline 2 & - & MSS1 & - & W4 & L1 & Strategy \\
\hline 3 & - & MSS4 & M2 & W6 & - & Organizational Structure \\
\hline 4 & $\mathrm{H} 3$ & - & - & - & - & Roles and Responsibilities \\
\hline 5 & - & MSS2, MSS6 & - & W1 & - & Management Support \\
\hline 6 & - & MSS8 & - & W8 & L4 & Motivational Encouragement \\
\hline 7 & $\mathrm{H} 5$ & MSS3 & M5 & W5 & L6 & Performance measurement \\
\hline 8 & $\mathrm{H} 2$ & MSS7 & M1 & W2 & L3 & Culture \\
\hline 9 & - & MSS5 & - & - & - & Organizational Learning \\
\hline 10 & - & - & - & W10 & - & Training and Education \\
\hline 11 & - & - & - & - & L5 & Organizational Infrastructure \\
\hline 12 & - & - & - & W9 & - & Resources \\
\hline 13 & - & - & - & W11 & - & Human Resources Management \\
\hline 14 & - & MSS9 & - & - & - & Communication and Group Working \\
\hline 15 & - & MSS11 & M4 & W7 & - & Processes and Activities \\
\hline 16 & $\mathrm{H} 4$ & MSS10 & M3 & W3 & L7 & IT Infrastructure \\
\hline 17 & - & MSS12 & - & - & - & Security \\
\hline 18 & - & - & - & - & L8 & Knowledge Transfer Channel \\
\hline
\end{tabular}

yang diusulkan oleh penelitian sebelumnya oleh Rao [4], yang mengajukan lima tingkatan kesiapan. Selain itu, penelitian Nugroho, yang berjudul Analisis Pengukuran Tingkat Kesiapan Implementasi Knowledge Management pada Perusahaan PT. XYZ [7] melakukan instrumen penilaian menggunakan metode analisis Gap Taylor dan Schellenberg. Sementara, tingkat kesiapan KM atau KM readiness level diambil dari penelitian sebelumnya oleh Rao [4] yang menghasilkan lima tingkat kesiapan KM. Penggunaan skala interval untuk menentukan level kesiapan mengacu pada perhitungan Cobit 4.1.

\section{Metode}

Penelitian yang dilakukan ini menggunakan metode Analisis Deskriptif Kuantitatif dengan menggunakan kuesioner yang disebarkan kepada responden penelitian. Adapun urutan yang dilakukan adalah sebagaimana ditunjukkan Gambar 1.

\section{Populasi dan Sampel}

Populasi dan sampel yang digunakan adalah pegawai dan pimpinan yang ada di Divisi IT, PT " $\mathrm{X}$ " sebanyak 68 responden, dengan pertimbangan bahwa pada umumnya individu yang ada memiliki literasi komputer yang dapat memahami kuesioner yang disampaikan.

\section{Metode Pengumpulan Data}

Kuesioner disebar dalam dua bentuk, yaitu dalam bentuk elektronik (melalui email menggunakan Google Form) dan dalam bentuk hardcopy untuk diisi oleh responden, hasilnya kemudian diubah da- lam bentuk database yang dapat diproses menggunakan aplikasi pengolah data statistik.

\section{Metode Analisis Data}

Langkah-langkah yang dilakukan dalam menganalisis data adalah sebagaimana terdapat Gambar 1 . Data dari hasil perhitungan jawaban responden dikelompokkan ke dalam tabel sesuai dengan aspek penilaian Knowledge Management Readiness yaitu Strategy, Organization, Culture, Technology, Motivation, Process, dan Human Resources.

Seluruh data hasil jawaban kemudian diolah menggunakan SPSS untuk diuji validitas dan reliabilitasnya. Dari hasil uji validitas dan reliabilitas diketahui terdapat 5 item yang tidak valid, sehingga menyisakan 74 item pertanyaan. Dari 74 item pertanyaan tersebut tidak terdapat item yang tidak reliable, sehingga hanya 74 item tersebut yang akan dianalisis. Kuesioner yang telah melalui uji validitas dan reliabilitas.

Skor untuk setiap item pertanyaan untuk seluruh responden dijumlahkan dan diambil rata-ratanya sebagai skor untuk item tersebut. Jumlah skor untuk tiap aspek diambil rata-ratanya untuk mengetahui tingkat kesiapan tiap aspeknya. Jumlah skor untuk semua aspek kemudian dijumlahkan untuk di-ambil rata-rata keseluruhannya untuk mengetahui tingkat kesiapan secara umum.

Berdasarkan hasil perhitungan secara keseluruhan, maka dapat dilakukan analisis dan interpretasi data sebagai dasar untuk mengambil kesimpulan dan membuat saran-saran perbaikan berdasarkan penelitian yang dilakukan. Item-item pertanyaan yang skor rata-ratanya di bawah 2,00 dianggap perlu mendapat perhatian dan diberikan saran untuk meningkatkan tingkat kesiapan. Untuk me- 


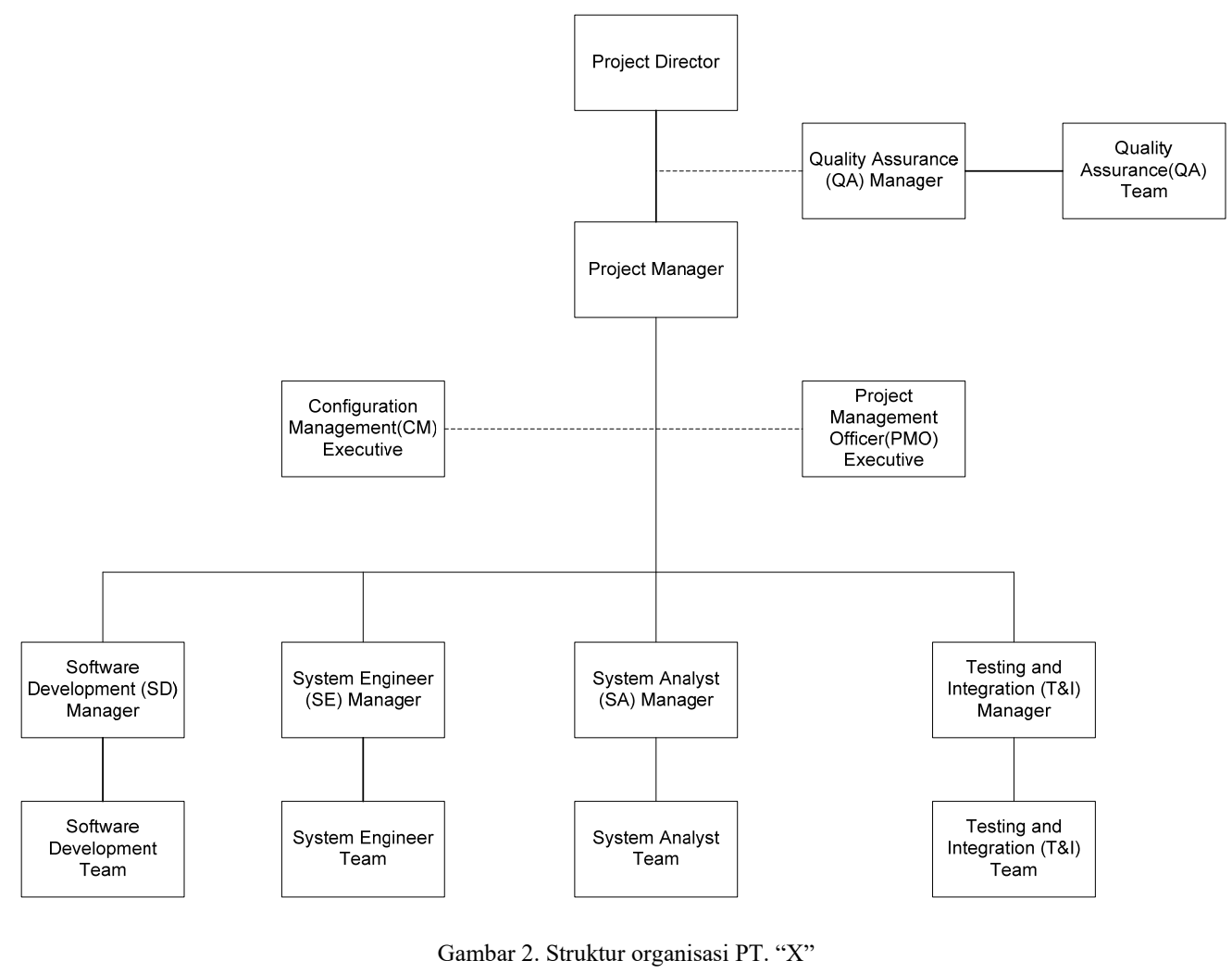

ngukur tingkat kesiapan knowledge management, digunakan skala Knowledge Management Readiness Level (Not Ready, Preliminary, Ready, Receptive, dan Optimal). Lebih lengkap mengenai Knowledge Management Readiness.

\section{Lokasi Penelitian}

Penelitian ini mengambil sample dari pegawai yang berada di Divisi IT, PT " $X$ " di Jakarta. PT. "X" adalah perusahaan yang bergerak dalam bidang konsultan IT. Indonesia merupakan sebuah perusahaan yang bergerak dibidang solusi teknologi informasi. Perusahan ini menyediakan jasa dan produk teknologi informasi yang dibutuhkan costumer. Sebagai perusahaan yang bergerak di bidang teknologi informasi, perusahaan dituntut untuk melakukan delivery product yang cepat dan tepat waktu. Setiap sumber daya manusia yang terlibat dituntut untuk saling bekerja sama. Pengalaman masingmasing sumber daya manusia dalam pengerjaan sebuah proyek menjadikan masing-masing sumber daya manusia memiliki keahlian yang berbeda-beda. Pengalaman dan keahlian sumber daya manusia ini menjadi salah satu sumber kekayaan perusahaan yang perlu dikelola. Adapun struktur organisasi PT. "X" ini dapat dilihat pada Gambar 2.

\section{Hasil dan Analisis}

Penelitian ini dimulai dengan menentukan faktor apa saja yang menentukan kesuksesan implementasi KM. Terdapat beberapa ahli yang membicarakan masalah Faktor-Faktor yang mempengaruhi kesuksesan KM yang dapat dipetakan seperti pada Tabel 1.

Dari pemetaan KMCSF para peneliti pada Tabel 1, terdapat 18 faktor yang menjadi Kunci Sukses KM, yaitu:

Leadership menilai bagaimana kepemimpinan para manajer dan pemimpin yang ada pada organisasi. Strategy, yaitu mengenai bagaimana strategi perusahaan dalam menerapkan KM, apakah ada strategi khusus yang diterapkan. Jika ada bagaimana strategi tersebut, apakah mudah direalisasikan atau tidak.

Organizational Structure, mengenai bagaimana struktur organisasi yang ada, apakah mendukung proses $\mathrm{KM}$, atau memberikan jarak antara karyawan dengan pimpinan, sehingga menyulitkan dalam transfer knowledge, atau apakah struktur tersebut mendukung proses transfer knowledge.

Roles and Responsibilities, yaitu pembagian peran dan tanggung jawab yang ada pada organisasi, pembagian peran dan tanggung jawab harus jelas, agar masing-masing karyawan dapat leluasa 


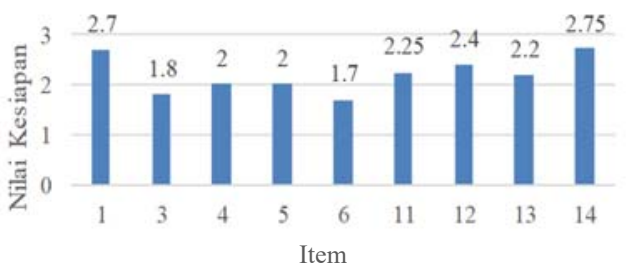

(a)

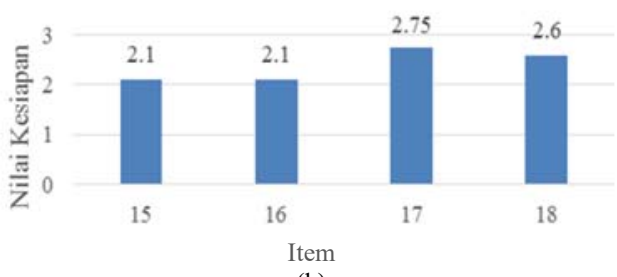

(b)

Gambar 3. Grafik tingkat kesiapan pada aspek (a) strategy dan (b) culture

melakukan tugasnya, mirip dengan struktur organisasi namun, struktur organisasi lebih menekankan pada hubungan antara satu peran dengan peran lain.

Management Support, yaitu tentang bagaimana bentuk dukungan yang diberikan manajemen terhadap para karyawan dalam menjalankan visi untuk menerapkan KM, apakah pihak manajemen serius memberikan dukungannya kepada karyawan atau tidak.

Motivational Encouragement, adalah mengenai bagaimana cara perusahaan memberikan motivasi kepada karyawan, agar karyawan mau berbagi pengetahuan dan menjadikan hal tersebut sebagai budaya yang tidak merugikan jika dilakukan, contohnya dengan pemberian imbalan kepada mereka yang melakukan knowledge sharing.

Performance measurement mengenai bagaimana pengukuran yang dilakukan organisasi terhadap penerapan KM, sebelum menerapkan KM, ditetapkan ukuran seperti apa yang diharapkan dapat diberikan KM terhadap kemajuan bisnis perusahaan, dan setelah menerapkan KM apakah penerapan KM tersebut mendukung jalannya bisnis perusahaan atau merugikan perusahaan.

Culture adalah mengenai bagaimana budaya para karyawan yang ada di organisasi. Sementara organizational learning adalah mengenai bagaimana proses pembelajaran yang ada pada organisasi tersebut berjalan, apakah organisasi memiliki media yang menyediakan atau memfasilitasi proses belajar, misalnya memberikan akses dokumentasi bagi karyawan yang membutuhkan dan apakah organisasi melakukan proses benchmark dengan perusahaan lain yang sejenis.

Training and Education, yaitu apakah organisasi mempersiapkan program pelatihan dan pendidikan terhadap karyawan, agar karyawan memiliki pemahaman yang baik tentang KM.

Organizational Infrastructure, menelaah infrastruktur yang ada pada organisasi yang mendukung proses penerapan KM, infrastruktur organisasi tersebut mendukung penerapan infrastruktur IT, contohnya jaringan listrik yang memadai untuk mendukung penggunaan komputer.
Resources yaitu bagaimana sumber daya yang dimiliki oleh organisasi tersebut, apakah sumber daya yang ada dapat melakukan peran yang berhubungan dengan penerapan KM.

Human Resources Management, tentang bagaimana pihak HR dalam organisasi mendukung proses penerapan KM ini, contohnya dalam proses perekrutan karyawan, HR mulai memperhatikan kemampuan calon karyawan yang mendukung proses penerapan KM.

Communication and Group Working adalah bagaimana gaya komunikasi dan cara bekerja para karyawan dalam kelompok. Processes and Activities, membahas mengenai bagaimana proses dan aktivitas yang ada di organisasi, apakah sudah mengadopsi proses-proses yang mendukung penerapan $\mathrm{KM}$ dan saling terintegrasi serta mendukung proses bisnis perusahaan atau belum.

IT Infrastructure adalah bagaimana infrastruktur teknologi yang ada di organisasi. Sedangkan security adalah bagaimana desain keamanan yang diterapkan terhadap sistem KM yang akan diterapkan.

Terakhir adalah knowledge Transfer Channel yang berhubungan dengan faktor bagaimana pengetahuan tersebut ditransfer dan dibagikan (misalnya Internet, Intranet, manual, dokumen, tatap muka, dan sebagainya).

Penelitian Nugroho, memetakan ke 18 faktor di atas menjadi tujuh faktor seperti yang terlihat pada Tabel 2. Berdasarkan penelitian tersebut maka faktor yang akan dijadikan kriteria kesiapan ada tujuh aspek, yaitu Strategy, Organization, Culture, Technology, Motivation, Process, dan Human Resources.

Alat uji yang akan disusun menggunakan pendekatan ke-7 Aspek di atas dengan menjabarkan kedalam indikator-indikator tiap-tiap aspek. Hasil dari penjabaran tiap aspek tersebut dapat dilihat pada Tabel 3.

Dari indikator pada Tabel 3, kemudian diturunkan menjadi pernyataan-pernyataan yang digunakan untuk menyusun kuesioner. Setelah kuisioner tersusun maka perlu dilakukan uji reliabilitas dan validitas pada untuk mendapatkan pernyataan yang valid dan reliable sebagai bagian yang akan 


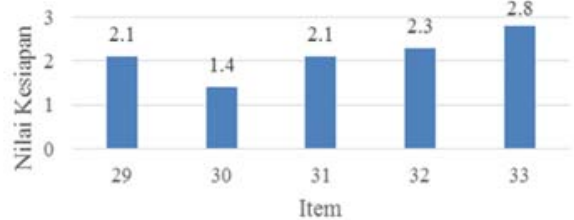

(a)

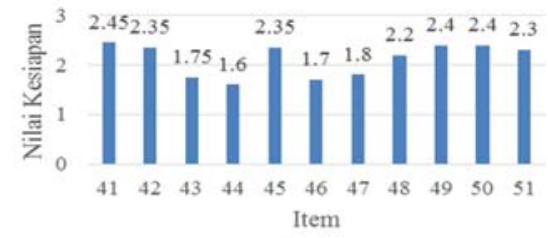

(c)

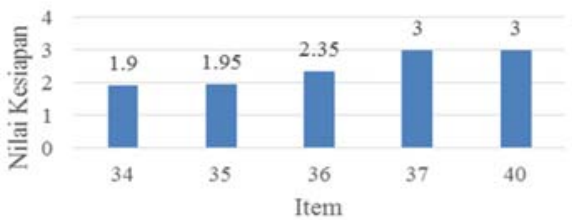

(b)

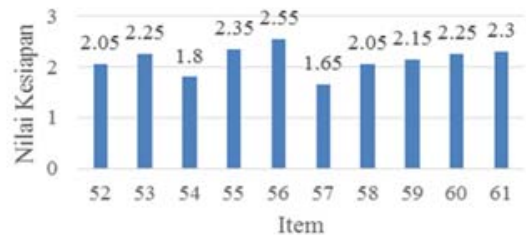

(d)

Gambar 4. Grafik tingkat keiapan pada aspek (a) organization, (b) motivation, (c) human resource, dan (d) technology

dimasukkan untuk perhitungan faktor readinessnya. Dari proses tersebut diperoleh hasil sebagai berikut:

\section{Aspek Strategy}

Dari Gambar 3a dapat dilihat bahwa item yang memiliki nilai kesiapan paling tinggi adalah item 14, yaitu pihak manajemen mendukung karyawan agar aktif mengeluarkan ide. Namun, disisi lain terdapat dua item yang memerlukan perhatian karena memiliki nilai di bawah 2,00 .

\section{Aspek Culture}

Berdasarkan hasil perhitungan seperti ditunjukkan pada Gambar 3b, tingkat kesiapan pada aspek culture memiliki nilai sebesar 2,39 yang artinya berada pada level ready. Penilaian ini menunjukkan bahwa budaya yang ada pada organisasi sudah menunjukkan beberapa kegiatan knowledge management sudah dilakukan setiap waktu dan pada setiap pekerjaan, seperti adanya budaya bekerja sama dan berbagi pengetahuan. Namun budaya ini belum diatur dalam peraturan organisasi dan belum teratur dan berkala. Meskipun budaya bekerja sama dan berbagi pengetahuan memang sudah berjalan dengan baik namun budaya untuk mendokumentasikan pengetahuan dan membagikan dokumentasi tersebut kepada karyawan lainnya belum menjadi kebiasaan yang teratur dilakukan di PT "X". Budaya kerja sama dan berbagi pengetahuan dilakukan ketika menghadapi masalah atau isu yang perlu didiskusikan bersama.

\section{Aspek Organization}

Dari grafik pada Gambar 4a dapat dilihat bahwa item yang memiliki nilai kesiapan tertinggi adalah item 33, yaitu bahwa setiap anggota tim percaya bahwa semua anggota tim memiliki pengetahuan/ keahlian masing-masing. Namun, disisi lain terdapat item yang memerlukan perhatian karena memiliki nilai di bawah 2,00.

\section{Aspek Motivation}

Berdasarkan hasil perhitungan seperti terlihat pada Gambar 4b, tingkat kesiapan pada aspek motivation memiliki nilai sebesar 2,44 yang artinya berada pada level ready. Penilaian ini menunjukkan bahwa adanya penghargaan bagi karyawan yang melakukan aktivitas knowledge namun belum ditetapkan dalam peraturan organisasi dan belum berjalan dengan baik. Perusahaan sebenarnya sudah menerapkan strategi promosi untuk memotivasi para karyawan lain untuk aktif berbagi ide dan pengetahuan namun penilaian dibalik promosi tersebut belum dilaksanakan secara terbuka dan konsisten karena belum terdapat sistem/pihak yang mencatat aktivitas tersebut secara konsisten atau peraturan yang jelas yang mengatur aktivitas tersebut. Dari penilaian ini dapat dilihat juga bahwa para karyawan sudah memiliki dorongan/motivasi untuk mencari dan berbagi pengetahuan. Aspek motivation memiliki lima item pengukuran yang dianggap dapat menghasilkan jawaban yang valid dan reliable.

\section{Aspek Human Resource}

Aspek human resources memiliki 11 item pengukuran yang dianggap dapat menghasilkan jawaban yang valid dan reliable. Nilai kesiapan tertinggi adalah item 41 (lihat Gambar 4c), yaitu tentang adanya kesempatan peningkatan karir di PT "X". Namun, disisi lain terdapat item yang memerlukan perhatian karena memiliki nilai di bawah 2,00. 


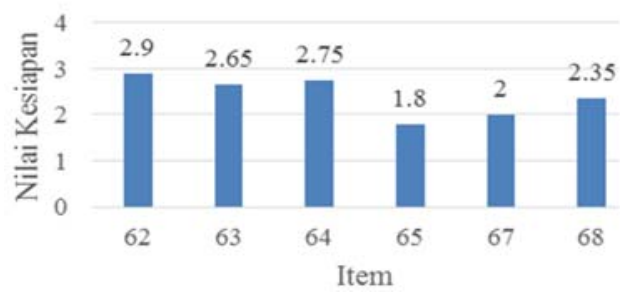

Gambar 5. Grafik tingkat kesiapan pada aspek process

\section{Aspek Technology}

Berdasarkan hasil perhitungan (lihat Gambar 4d), tingkat kesiapan pada aspek technology memiliki nilai sebesar 2,14 yang artinya berada pada level ready. Penilaian ini menunjukkan bahwa dukungan teknologi seperti penggunaan ICT, fasilitas internet dan intranet sudah ada namun dinilai belum mendukung proses penerapan knowledge management. Fasilitas ICT yang ada pada perusahaan masih diutamakan untuk proses komunikasi dan menyelesaikan pekerjaan bukan untuk mendukung proses penerapan knowledge management. Dapat dilihat dari belum adanya proses katalogisasi dan prosedur pengarsipan yang tercantum dalam aturan organisasi. Pengamanan terhadap teknologi informasi sudah ada namun belum terlalu diperhatikan dengan serius, dapat dilihat dari belum adanya prosedur keamanan berkaitan dengan data dan informasi yang tercantum dalam aturan organisasi. Perusahaan sebenarnya sudah menyadari bahwa fasilitas IT dapat mendukung proses penerapan knowledge namun belum ada tindakan nyata yang dilaksanakan untuk mewujudkannya.

Aspek technology memiliki 10 item pengukuran yang dianggap dapat menghasilkan jawaban yang valid dan reliable. Dari grafik tersebut dapat dilihat bahwa item yang memiliki nilai kesiapan tertinggi adalah item 56, yaitu tentang adanya pemahaman yang sama bahwa penggunaan IT memudahkan komunikasi antarkaryawan. Namun, di sisi lain terdapat item yang memerlukan perhatian karena memiliki nilai di bawah 2,00.

\section{Aspek Process}

Berdasarkan hasil perhitungan (lihat Gambar 5), tingkat kesiapan pada aspek process memiliki nilai sebesar 2,41 yang artinya berada pada level ready. Penilaian ini menunjukkan bahwa proses $\mathrm{kn}$ owledge sudah terjadi dalam organisasi pada setiap kegiatan pekerjaan, seperti adanya kegiatan-kegiatan berbagi ide dan pengetahuan namun kegiatan tersebut belum memiliki standar tertentu dan belum tercantum dalam aturan. Penilaian juga menunjukkan bahwa belum adanya proses klasifikasi
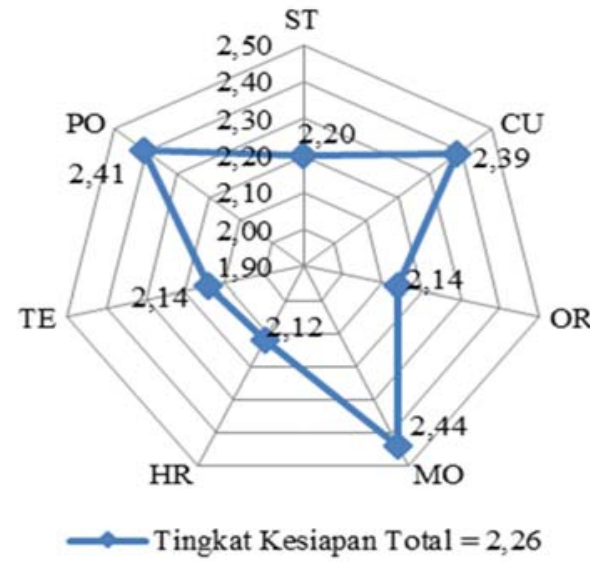

Gambar 6. Grafik radar hasil analisis secara keseluruhan

dan penyimpanan pengetahuan secara efektif, dan hal ini mempengaruhi proses pencarian dokumentasi pengetahuan sulit ditemukan.

Aspek process memiliki enam item pengukuran yang dianggap dapat menghasilkan jawaban yang valid dan reliable.

Penghitungan Nilai Total

Tampilan grafik radar hasil analisis secara keseluruhan dapat dilihat pada Gambar 6.

\section{Kesimpulan}

Hasil pengukuran tingkat kesiapan Divisi IT, PT. "X" Jakarta dalam mengimplementasikan KM berada pada level 3, yaitu ready, dengan nilai 2,26. Hal ini menunjukkan bahwa departemen pengembangan sistem Divisi IT, PT. "X" Jakarta sudah siap menerapkan knowledge management. Divisi IT, PT. "X" Jakarta masih memiliki beberapa aspek yang perlu diperhatikan seperti aspek human resource, organization, dan teknologi.

Penulis merekomendasikan langkah-langkah yang perlu dilakukan Divisi IT, PT. "X" Jakarta untuk meningkatkan aspek-aspek yang dinilai belum siap dalam mengimplementasikan KM tersebut, yaitu:

Untuk aspek human resources, perusahaan mulai memperhatikan dan mengadakan kesempatan bagi karyawan untuk meningkatkan kemampuan profesional mereka, melalui pelatihan, workshop, atau aktivitas lain yang bertujuan untuk pengembangan pengetahuan karyawan secara profesional. Perusahaan diharapkan dapat membantu dan memfasilitasi karyawan untuk mencari program pelatihan atau workshop, terlebih kepada karyawan yang membutuhkan pelatihan atau workshop tersebut karena tuntutan pekerjaan. 
TABEL 3

INDIKATOR UNTUK TIAP-TIAP FAKTOR

\begin{tabular}{ll}
\hline Faktor yang di- & Indikator \\
usulkan & Karyawan memiliki pemahaman yang sama mengenai pentingnya KM \\
Strategy & Perusahaan memiliki strategi dan inisiatif untuk menerapkan KM \\
& Perusahaan mengetahui bahwa terdapat kebutuhan untuk mengelola pengetahuan \\
& Adanya pengukuran terhadap penerapan KM \\
& Pihak manajemen mengarahkan dan mendukung proses penerapan KM \\
& Adanya budaya untuk mendokumentasikan pengetahuan dan berbagi pengetahuan \\
Culture & Adanya budaya untuk bekerja sama dan saling berkomunikasi untuk memecahkan suatu masalah \\
& Adanya peran serta karyawan dalam berbagi pengetahuan dan belajar pengetahuan baru \\
Organization & Struktur dalam organisasi memudahkan karyawan untuk berkomunikasi dan mengeluarkan ide \\
& Adanya tim khusus yang dibentuk untuk mendukung penerapan KM \\
& Adanya wadah yang kondusif yang disediakan untuk berbagi pengetahuan \\
Motivation and Re- & Setiap karyawan mengetahui peta penyimpanan knowledge \\
Adanya monitoring dan penghargaan terhadap peran karyawan dalam penerapan KM \\
Human Resources & Adanya pemahaman mengenai manfaat berbagi pengetahuan \\
& Perusahaan membuka kesempatan peningkatan karir dan menciptakan lingkungan kerja yang me- \\
& nyenangkan bagi karyawan \\
Adanya inisiatif peningkatan pengetahuan perusahaan melalui proses perekrutan karyawan \\
Technology & Proporsi sumber daya manusia dalam perusahaan merata \\
Process and Activity & Penggunaan fasilitas TI untuk berbagi pengetahuan \\
& Ketersediaan fasilitas TI dalam pengelolaan pengetahuan \\
& Adanya proses menciptakan dan berbagi pengetahuan antar karyawan dalam bekerja \\
& Perusahaan aktif menggunakan pengetahuan dalam proses menghasilkan produk dan jasa \\
\hline
\end{tabular}

Untuk aspek organization, perusahaan sebaiknya memiliki tim khusus yang mendukung penerapan knowledge management, sehingga segala sesuatu yang diperlukan untuk penerapan knowledge management dapat ditindaklanjuti dengan tindakan nyata. Hal ini dapat menjadi perwujudan dari strategi-strategi yang sudah dimiliki perusahaan.

Untuk aspek teknologi, perusahaan sebaiknya mulai memikirkan untuk menyediakan fasilitas IT yang bukan hanya untuk mendukung proses komunikasi dan kelancaran pekerjaan, namun yang juga mendukung proses belajar, share knowledge, sistem pengelolaan dokumen, integrasi data.

Masih banyak faktor-faktor lain yang menjadi faktor sukses dalam implementasi KM yang belum dimasukkan kedalam model kesiapan (readiness) KM, seperti yang model KMCSF yang dikemukakan oleh peneliti Bots dan de Bruijn [8], Massey [9], Lindsey [10], Jennex [11] dan Maier [12], dll yang dapat dijadikan acuan pengukuran kesiapan KM (KM Readiness).

\section{Referensi}

[1]. Fujita, Y., Shiono, Y., \& Maki, K. (2014). Knowledge of emergency management of avulsed tooth among Japanese dental students. BMC oral health, 14(1), 1.

[2]. Airlangga Agung Perdana, "Analisis Pengukuran Tingkat Kesiapan Implementasi Knowledge Management Di Pusat Sistem Informasi Dan Teknologi Keuangan Kementrian Keuangan”, Universitas Indonesia, 2014.
[3]. Sukomo dan Pandu Arizona, "Analisis Pengukuran Tingkat Kesiapan Implementasi Knowledge Management (KM Readiness) : Studi Kasus Pusat Ilmu Komputer Universitas Indonesia”. Universitas Indonesia, 2012.

[4]. Rao-Madanmohan, "Knowledge Management Tools and Technique: Practicioner and Experts evaluate KM Solution”, Butterworth -Heinemann, 2004.

[5]. Zaidiah-Ati. "Analisis Tingkat Kesiapan $\mathrm{Kn}$ owledge Management pada Sekretariat Badan Pendidikan dan Latihan Kementerian Pertahanan Republik Indonesia”. Universitas Indonesia, 2011.

[6]. Pradana Atmadiputra, "Analisis Tingkat Kesiapan Implementasi Knowlege Management (Knowledge Management Readiness) di Departemen Microsoft Operation PT. Astra Graphia Information Technology", Universitas Indonesia, 2014.

[7]. Nugroho, "Analisis Pengukuran Tingkat Kesiapan Implementasi Knowledge Management Pada Perusahaan PT. XYZ", Universitas Indonesia, 2014.

[8]. Bots, Pieter WG, and Hans de Bruijn. "Effective knowledge management in professional organizations: going by the rules." In System Sciences, 2002. HICSS. Proceedings of the 35th Annual Hawaii International Conference on, pp. 11-pp. IEEE, 2002.

[9]. Massey, Anne P., Mitzi M. Montoya-Weiss, and Tony M. O'Driscoll. "Knowledge management in pursuit of performance: Insights from Nortel Networks." MIS quarterly (2002): 269-289. 
[10]. Lindsey, Keith. "Measuring knowledge management effectiveness: A task-contingent organizational capabilities perspective." AMCIS 2002 Proceedings (2002): 285.

[11]. Jennex, Murray, and Lorne Olfman. "Assessing knowledge management success." International Journal of Knowledge Management (IJKM) 1, no. 2 (2005): 33-49.

[12]. Maier, Ronald. "Motivation" In Knowledge Management Systems, pp. 1-7. Springer Berlin Heidelberg, 2004.

[13]. Hasanali, F., 2002. Critical success factors of knowledge management.

[14]. Mamaghani, N.D., Samizadeh, R. and Saghafi, F., 2011. Evaluating the readiness of Iranian research centers in knowledge management. American Journal of
Economics and Business Administration, 3(1), p.203.

[15]. Mathi, K., 2004. Key success factors for knowledge management. MBA: International Business Management\& Consulting. Master thesis.

[16]. Yew Wong, K., 2005. Critical success factors for implementing knowledge management in small and medium enterprises. Industrial Management \& Data Systems, 105(3), pp.261-279.

[17]. Mercadoa, L.C.C., 2010. Influence of Critical Success Factors of Knowledge Management on the Innovation Performance of Colombian Organizations. In Eighth LACCEI Latin American and Caribbean Conference for Engineering and Technology (LACCEI). 